\title{
Base-free Suzuki-Miyaura cross-coupling reaction mediated by Lewis acids
}

Authors: Takashi Niwa ${ }^{1 *}$, Yuta Uetake ${ }^{2,3 *}$, Motoyuki Isoda ${ }^{1} \uparrow$, Tadashi Takimoto ${ }^{1}$, Miki Nakaoka $^{1}$, Daisuke Hashizume ${ }^{4}$, Hidehiro Sakurai ${ }^{2,3}$, Takamitsu Hosoya ${ }^{1,5}$

\section{Affiliations:}

${ }^{1}$ Laboratory for Chemical Biology, RIKEN Center for Biosystems Dynamics Research (BDR); Kobe, 650-0047, Japan.

${ }^{2}$ Division of Applied Chemistry, Graduate School of Engineering, Osaka University; Suita, Osaka, 565-0871, Japan.

${ }^{3}$ Innovative Catalysis Science Division, Institute for Open and Transitionary Research Initiative (ICS-OTRI), Osaka University; Suita, Osaka 565-0871, Japan.

${ }^{4}$ RIKEN Center for Emergent Matter Science (CEMS); Wako, Saitama, 351-0198, Japan.

${ }^{5}$ Laboratory of Chemical Bioscience, Institute of Biomaterials and Bioengineering, Tokyo Medical and Dental University (TMDU); Chiyoda-ku, Tokyo, 101-0062, Japan.

*Corresponding author. Email: takashi.niwa@riken.jp, uetake@chem.eng.osaka-u.ac.jp

$\dagger$ Present address: School of Pharmacy at Fukuoka, International University of Health and Welfare; Okawa, Fukuoka, 831-8501, Japan.

\begin{abstract}
:
The palladium-catalyzed Suzuki-Miyaura cross-coupling (SMC) reaction of organohalides and organoborons is a reliable carbon-carbon bond-forming method. This reaction involves a basemediated transmetalation process, but the presence of a base also promotes competitive protodeborylation, which reduces the efficiency. Herein, we established a base-free SMC reaction via Lewis acid-mediated transmetalation of an organopalladium(II) intermediate with organoborons. Experimental and theoretical investigations indicate that the controlled release of the transmetalation-active intermediate enabled base-free transmetalation under heating conditions and enhanced the applicable scope of this process. This system enabled us to avoid the use of a base, and thus, rendered substrates with base-sensitive moieties available. Results from this research further expand the utility of cross-coupling chemistry overall.
\end{abstract}




\section{Main Text:}

The Suzuki-Miyaura cross-coupling (SMC) reaction is one of the reliable carbon-carbon bond forming processes, broadly applied in the synthesis of valuable compounds, such as pharmaceuticals. $^{1,2}$ A critical step in the SMC reaction is the transmetalation of organopalladium(II) species with organoborons, which conventionally requires the presence of a base. ${ }^{3}$ Basic conditions, however, also occasionally cause undesired protodeborylation, particularly when using industrially-valuable organoborons, such as perfluoroaryl- and heteroarylborons (Fig. 1A). ${ }^{4,5}$ This issue has been recognised as a "base problem", ${ }^{6}$ and therefore, numerous efforts have been made to suppress the side reaction to broaden the range of synthetically available chemical structures and promote developing socially-worthful materials. ${ }^{7,8}$ A straightforward approach to solving the base problem is to avoid the addition of a base. Indeed, the SMC reaction has been shown to be possible without a base under exceptional conditions, such as employing specific substrates. For example, transmetalation can occur with organo(trialkoxy)borates without an additional base because of their high nucleophilicity. ${ }^{9,10}$ Sanford et al. has recently reported that using of acyl fluorides as electrophiles allows for a nickel-catalysed SMC reaction with organoboronic acids without an exogenous base, in which the fluoride within the substrates promotes transmetalation. ${ }^{11}$ The SMC reaction is also known to occur without a base or heating when aryldiazonium salts are employed as electrophiles, in which the transmetalation of coordinately unsaturated cationic arylpalladium(II) with organoboronic acids proceeds (Fig. 1B). ${ }^{12-15}$ These pioneering works have solved the base problem by designing the substrates. Herein, we report a base-free SMC reaction of readily available organohalides with organoborons enabled by designing catalytic intermediates.

We focused on the reaction using aryldiazonium salts, which indicates that cationic organopalladium(II) species can potentially help developing a base-free SMC reaction (Fig. 1B). A challenge in realising this approach is the overcoming of the thermal instability of cationic arylpalladium(II) species, which limits the reaction temperature. ${ }^{13}$ Indeed, only an aryldiazonium salt can react with a palladium catalyst at room temperature to generate a cationic arylpalladium(II) complex via oxidative addition and liberation of dinitrogen, avoiding the necessity of heating. Considering that SMC reactions often require heating to complete a catalytic cycle, preventing the thermal decomposition of palladium intermediates is indispensable for generalising the base-free methodology as a reliable alternative to form carbon-carbon bonds.

To address this issue, we designed a coordinately saturated cationic organopalladium(II) intermediate with labile ligands that are thermally stable and release the corresponding unsaturated and transmetalation-active species in equilibrium (Fig. 1C). The controlled release of cationic organopalladium(II) species is expected to suppress the spontaneous degradation and prioritise the desired pathway even under heating conditions. We envisioned that this masked intermediate can be generated via the dehalogenation of an aryl(halo)palladium(II) complex with a halophilic Lewis acid, where the metal halides thus formed serve as a labile ligand. Conventionally, dehalogenation has often employed silver(I) salts, which are unsuitable for this plan because of their redox activities, which terminates the catalytic cycle via the oxidation of palladium(0) species. The low solubility of silver(I) halides in organic solvents is also problematic, as it is precipitated out without serving as a ligand. Hence, our investigation commenced with exploring Lewis acids that are suitable for our purpose. 

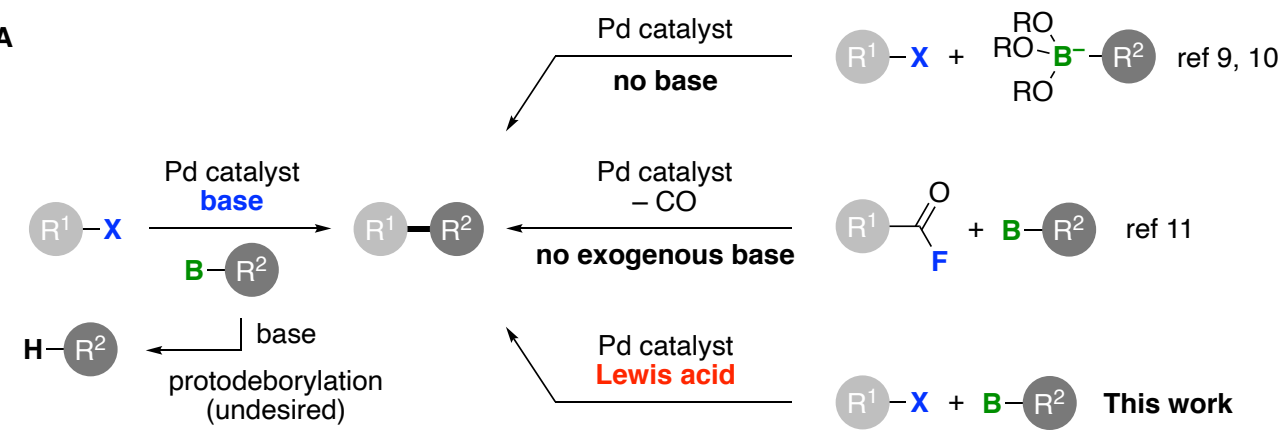

B Via cationic palladium(II) intermediate at room temperature (ref 12,13$)$

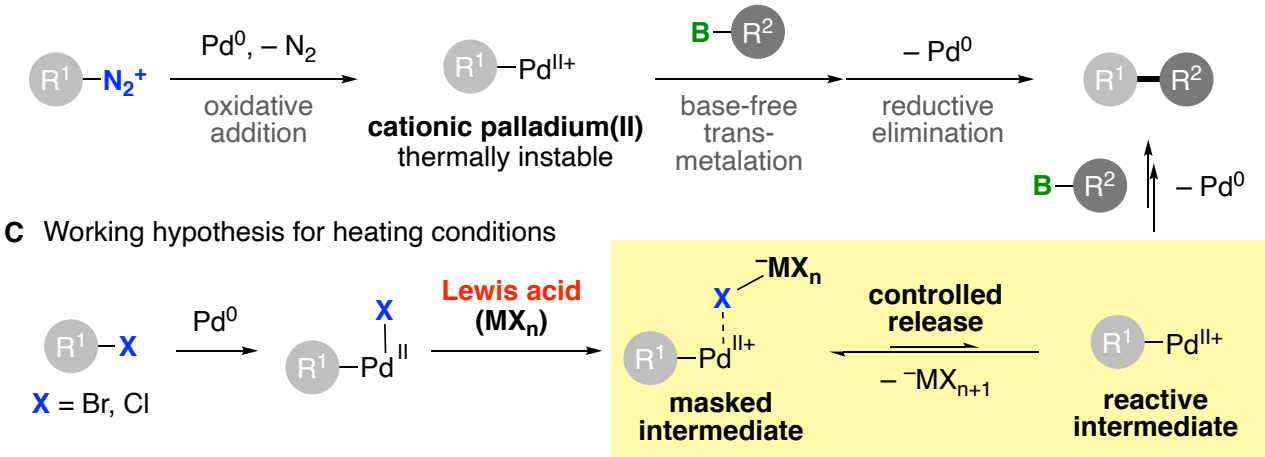

Fig. 1. Suzuki-Miyaura cross-coupling (SMC) reaction. A, Schemes of base-mediated and base-free SMC reactions. B, Base-free SMC reaction with aryldiazonium salts as electrophiles via the formation of a cationic arylpalladium(II) intermediate. C, Working hypothesis of a Lewis acid-mediated SMC reaction with organohalides via the controlled release of a cationic arylpalladium(II) intermediate. R: substituent; X: leaving group, unless otherwise noted; B: boryl group.

To verify our hypothesis, various halophilic metal salts were screened for the SMC reaction between aryl bromide $\mathbf{1}$ and a small excess of potassium phenyl(trifluoro)borate $\mathbf{2} \mathbf{a}^{16}$ in the presence of $\mathrm{PdCl}_{2}$ (amphos) $)_{2}$ at $80{ }^{\circ} \mathrm{C}$. During this process, we found several metal triflates that provided 4-fluorobiphenyl (3) (Fig 2A and Table S2). Among them, a zinc trimer, i.e., $[(\text { tmeda }) \mathrm{Zn}(\mathrm{OH})(\mathrm{OTf})]_{3}$ (4), easily prepared from zinc(II) triflate and $N, N, N^{\prime}, N^{\prime}-$ tetramethylethylenediamine (TMEDA), demonstrated the best result to afford $\mathbf{3}$ in quantitative yield. The use of indium(III) triflate also provided $\mathbf{3}$, while no conversion was observed when hard Lewis acids, such as boron trifluoride or a trifluoromethanesulfonic acid (HOTf), were added, suggesting that the halophilicity of the additives is crucial. The addition of silver salts resulted in a low conversion, in agreement with our assumption. A precise investigation revealed that a more than half of a zinc atom equivalent is essential for completing the reaction (Fig. 2B), which indicates that the zinc centre is responsible for two catalytic cycles. This result indicates that the hydroxy group of $\mathbf{4}$ is not necessary for the transformation because it should be removed from 4 if it serves as a base in the first cycle and not be involved within the second reaction. A screening study of palladium catalyst ligands showed that di- or tri(tertbutyl)phosphines, including Amphos, were preferable, whereas di- or tricyclohexylphosphines yielded poor results (Table S3). Other series of phenylboron derivatives, including phenylboronic acid (2b) and $N$-methyliminodiacetic acid (MIDA) derivative $\mathbf{2 f},{ }^{17}$ were 
applicable under these conditions, while the use of phenylboronic acid pinacol ester (2d) and phenyl(naphthalene-1,8-diamino)boron $(\mathbf{2 g})^{18}$ did not afford the product, demonstrating the unconventional selectivity of boronic acid esters structured for SMC reactions (Fig. 2C).

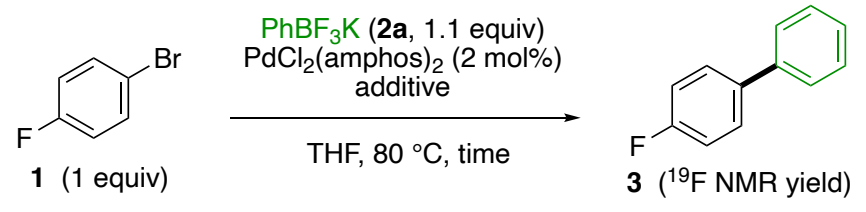

\begin{tabular}{|c|c|}
\hline \multicolumn{2}{|c|}{ A. Lewis acid screening (time: $3 \mathrm{~h}$ ) } \\
\hline additive & yield of $3(\%)$ \\
\hline 4 (0.72 equiv/Zn) & $>99$ \\
\hline $\mathrm{Zn}(\mathrm{OTf})_{2}(0.72$ equiv) & 50 \\
\hline $\ln (\mathrm{OTf})_{3}(0.72$ equiv) & 18 \\
\hline (tmeda) $\mathrm{ZnBr}_{2}$ (1.1 equiv) & 0 \\
\hline AgOTf (1.2 equiv) & 8 \\
\hline $\mathrm{AgBF}_{4}(1.2$ equiv) & 9 \\
\hline TMSOTf ( 2 equiv) & 0 \\
\hline $\mathrm{BF}_{3} \cdot \mathrm{OEt}_{2}$ (2 equiv) & 0 \\
\hline HOTf (1.2 equiv) & 0 \\
\hline TMEDA (2 equiv) & 0 \\
\hline $\mathrm{KHF}_{2}$ (2 equiv) & 0 \\
\hline B. Amount of 4 (time: $15 \mathrm{~h}$ ) & \\
\hline $\begin{array}{c}\text { Amount of } 4 \\
\text { (equiv/Zn) }\end{array}$ & yield of $3(\%)$ \\
\hline 0.72 & $>99$ \\
\hline 0.5 & 81 \\
\hline 0.4 & 59 \\
\hline 0.3 & 46 \\
\hline 0.2 & 31 \\
\hline 0.1 & 14 \\
\hline
\end{tabular}

C. Organoborons instead of $2 a$ with 4 ( 0.72 equiv/ $\mathrm{Zn}$, time: $3 \mathrm{~h})$

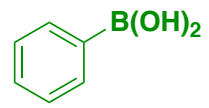

boronic acid (2b) $79 \%$ (1.1 equiv) $>99 \%$ (1.5 equiv)

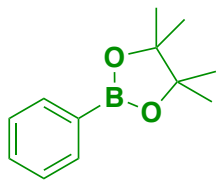

pinacol ester (2d) $0 \%$ (1.1 equiv)
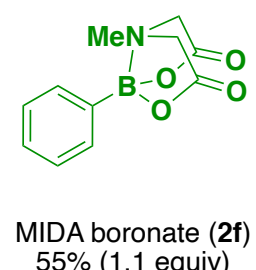
$55 \%$ (1.1 equiv)

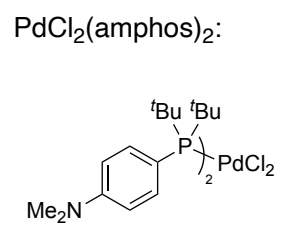

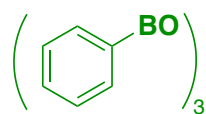

boroxine (2c) $91 \%(1.1$ equiv $)$ $74 \%$ ( 0.4 equiv)
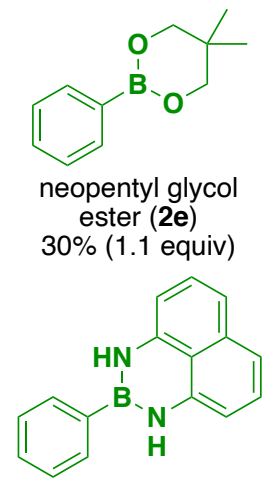

1,8-diaminonaphthalene amide (2g) $<1 \%(1.1$ equiv)

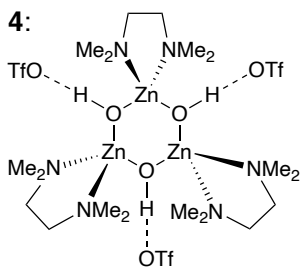

Fig. 2. Lewis acid-mediated base-free SMC reaction. Reaction conditions: 1 ( $0.20 \mathrm{mmol}, 1$ equiv), 2 ( $0.22 \mathrm{mmol}, 1.1$ equiv, unless otherwise noted), $\mathrm{PdCl}_{2}$ (amphos) $)_{2}(4 \mu \mathrm{mol}, 2 \mathrm{~mol} \%$ ), additive, THF $(1 \mathrm{~mL})$, under argon at $80{ }^{\circ} \mathrm{C}$. Yields were determined by ${ }^{19} \mathrm{~F}$ NMR with (trifluoromethyl)benzene as an internal standard. A, Optimization of additives. B, Investigation of the amount of 4 . $\mathrm{C}$, Scope of phenylboronic acid derivatives.

Stoichiometric reactions were conducted to confirm the role of the zinc complex. We synthesised aryl(bromo)palladium(II) dimer 5a and fully characterised its structure through single-crystal X-ray diffraction analysis (Fig. S2). Nuclear magnetic resonance (NMR) spectroscopy indicated that treatment of $\mathbf{5 a}$ with four equivalents of $\mathbf{4}$ produced a new species (Fig. 3A and Table S8), along with an insoluble zinc hydroxide oligomer (Fig. S7). The regeneration of 5a was observed by adding an excess amount of tetra( $n$-butyl)ammonium bromide (TBAB) to this mixture, which indicates that this intermediate (6) formed via debromination by zinc complex 4 (Table S9). Intermediate 6 showed significant reactivity to 
various phenylborons, as the reaction with several organoborons $\mathbf{2 a - c}$ was completed within 5 min to afford $\mathbf{3}$. The reactivity of $\mathbf{6}$ was compared with those of the related cationic palladium complexes ( $\mathbf{5 b}$ and $\mathbf{5 c})$, generated by the treatment of $\mathbf{5 a}$ with silver salts (Fig. 3B). The reaction between each palladium intermediate and $\mathbf{2 c}$, a well-dissolvable organoboron derivative in tetrahydrofuran (THF), occurred even at $-30{ }^{\circ} \mathrm{C}$. The reaction rate mediated by zinc complex 4 was comparable to that by silver tetrafluoroborate $\left(\mathrm{AgBF}_{4}\right)$, and higher than that by silver triflate (AgOTf). In contrast, a significant difference in stability was observed between the two groups. Namely, $\mathbf{6}$ remained unchanged for more than a day in THF- $d_{8}$ at $23{ }^{\circ} \mathrm{C}$, while the $\mathbf{5 b}$ and 5c smoothly decomposed at room temperature (Figs. S3-S5). These results indicate that 6 possesses both sufficient thermal stability and reactivity with organoborons owing to the presence of Zn species. The ${ }^{1} \mathrm{H}$ NMR spectra of $\mathbf{6}, \mathbf{5 b}$, and $\mathbf{5 c}$ demonstrated almost all signals in the aromatic region shifted to a low magnetic field, reflecting the electrophilically-activated nature of each palladium centre (Fig. 3C). Meanwhile, the aromatic proton of $\mathbf{6}$ at the orthoposition of the phosphine atom in the Amphos ligand (corresponding to $\mathbf{H}_{\mathbf{a}}$ of $\mathbf{5 a}$ in Fig. 3A) was an intriguing exception, which showed a slightly high magnetic field shift (Fig. 3C). These observations illustrated the definite structural differences between $\mathbf{6}$ and the others.

A

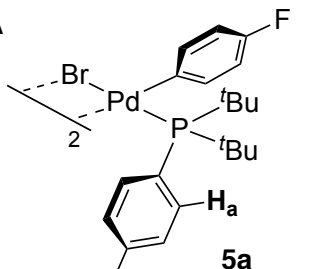

4 (4 equiv)

THF- $d_{8}$, rt, $10 \mathrm{~min}$

$\stackrel{- \text { Zinc hydroxide oligomer }}{\longleftarrow}$ intermediate 6

TBAB (10 equiv)

THF- $d_{8}, \mathrm{rt}, 15 \mathrm{~min}$

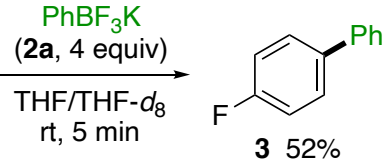

$\mathrm{Me}_{2} \mathrm{~N}$ (1 equiv as $\left.\mathrm{Pd}\right)$

4 (4 equiv)
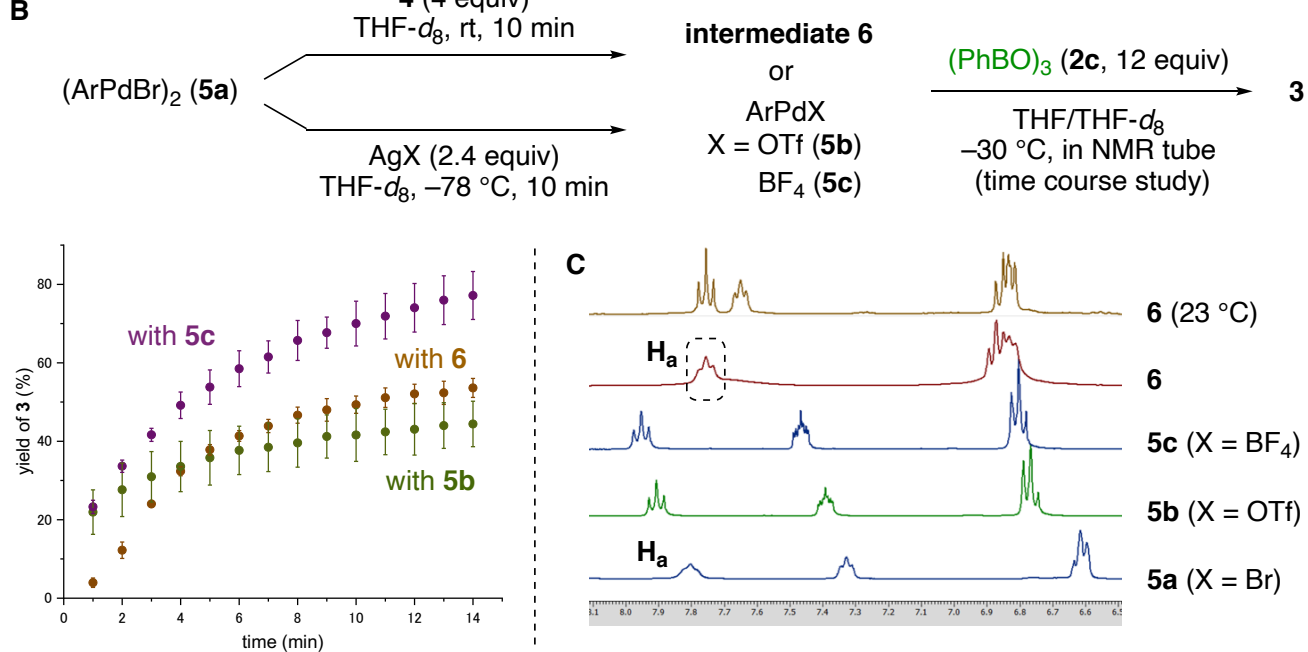

Fig. 3. Stoichiometric reactions. A, Generation of intermediate $\mathbf{6}$ and its reaction with $\mathbf{2 a}$. B, Generation of $\mathbf{6}$ and the related cationic palladium complexes $(\mathbf{5 b}$ and $\mathbf{5 c})$ and their reactions with $2 \mathbf{c}$ at $-30^{\circ} \mathrm{C}$. C, Enlarged view of ${ }^{1} \mathrm{H}$ NMR spectra in the aromatic region $(\delta 8.1-6.5 \mathrm{ppm})$ of $\mathbf{5 a}-\mathbf{c}\left(-30^{\circ} \mathrm{C}\right)$ and $\mathbf{6}\left(-30^{\circ} \mathrm{C}\right.$ and $\left.23^{\circ} \mathrm{C}\right)$.

To elucidate the origin of the characteristics of intermediate $\mathbf{6}$, structural analyses were carried out mainly by X-ray absorption spectroscopy (XAS). We performed in situ XAS experiments of 6 formed by mixing 5a and 4 in THF. In the Br-K edge extended X-ray absorption fine structure (EXAFS), the second peak (3.1 $)$ disappeared and the first peak (2.3 $\mathrm{A})$ shifted to the 
radial distance corresponding to the $\mathrm{Br}-\mathrm{Zn}$ scattering (2.0 $\mathrm{A}$ ) (Fig. 4A). This result also revealed that the zinc complex 4 plays a role in eliminating the bromine atom from the palladium centre. Pd-K edge EXAFS analysis of $\mathbf{6}$ indicated that, after the reaction, the singlet peak observed at the radial distance of $2.2 \AA$ was split into two peaks $(2.0$ and $2.6 \AA)$, which was attributed to the absence of bromine around the palladium centre (Fig. 4B). The second peak $(2.0 \AA)$ was assigned to Pd-P bonding. The third peak (2.6 ̊) implied the presence of a relatively heavy element, which could be assigned as the sulfur in triflate, indicating the formation of palladium triflate. Considering that the ${ }^{1} \mathrm{H}$ NMR spectrum of the intermediate 6 was not identical to that of palladium triflate $\mathbf{5 b}$ generated from AgOTf (Fig. 3C), we analyzed the XAS data on Zn-K edge in further detail. The X-ray absorption near edge structure (XANES) spectrum of 6 appeared to be intermediate features between those of the zinc complex 4 and (tmeda) $\mathrm{ZnBr}_{2}$ (Fig. 4C). In addition, the lower peak intensity of 6 compared with the reference (tmeda) $\mathrm{ZnBr}_{2}$ indicated that the coordination number of the bromine was one (Fig. 4D). These results suggest that zinc atom was connected with both bromide and oxygen atoms and that the local structure around zinc was $\mathrm{Br}-\mathrm{Zn}-\mathrm{O}$. Based on our comprehensive analysis of XAS results, we propose that intermediate 6 in THF solution represents the formation of a $\mathrm{Pd} / \mathrm{Zn}$ binuclear complex bridged by the triflate moiety.

Based on the local structure derived from XAS experiments, the entire structure was reconstructed using density functional theory (DFT) calculations at the B3PW91-D3/def2-SVP level of theory (Fig. 4E). Subsequently, the curve fitting of the Pd-K edge EXAFS of 6 was performed using the DFT-optimized structure as coordinates for calculating of scattering paths with the FEFF6 code. ${ }^{19}$ The fitting results in $r$-space $(1.2-3.0 \AA)$ of the magnitude and imaginary part are plotted in Fig. 4F. The variations of all fitting parameters were within reasonable values, and the $R$ factor was $1.28 \%$, suggesting a good coincidence (Table S14). The fitting confirmed that the third peak originated from the $\mathrm{Pd}-\mathrm{S}$ scattering. Overall, we conclude that the proposed triflate-bridged $\mathrm{Pd} / \mathrm{Zn}$ binuclear complex is the most plausible candidate for intermediate. The plausibility of this structure was also supported by the peak shift observed in ${ }^{1} \mathrm{H}$ NMR to a higher magnetic field $\left(\mathbf{H}_{\mathbf{a}}\right.$ in Fig. $\left.3 \mathrm{C}\right)$. Two-dimensional NMR and DFT analyses of $\mathbf{6}$ revealed that the aromatic proton $\mathbf{H}_{\mathbf{a}}$ at the ortho-position of the phosphine atom is directed toward the centre of the fluorophenyl group (Fig. S13) and is therefore magnetically shielded. The estimated structure does not involve the hydroxy group of 4, which indicates that this group does not serve as a base to promote the subsequent transmetalation with organoborons (Fig. $\mathrm{S} 15)$. Our conclusions are further supported by the observed formation of a zinc hydroxide oligomer as an insoluble byproduct when $\mathbf{6}$ was generated (Fig. 3A). 

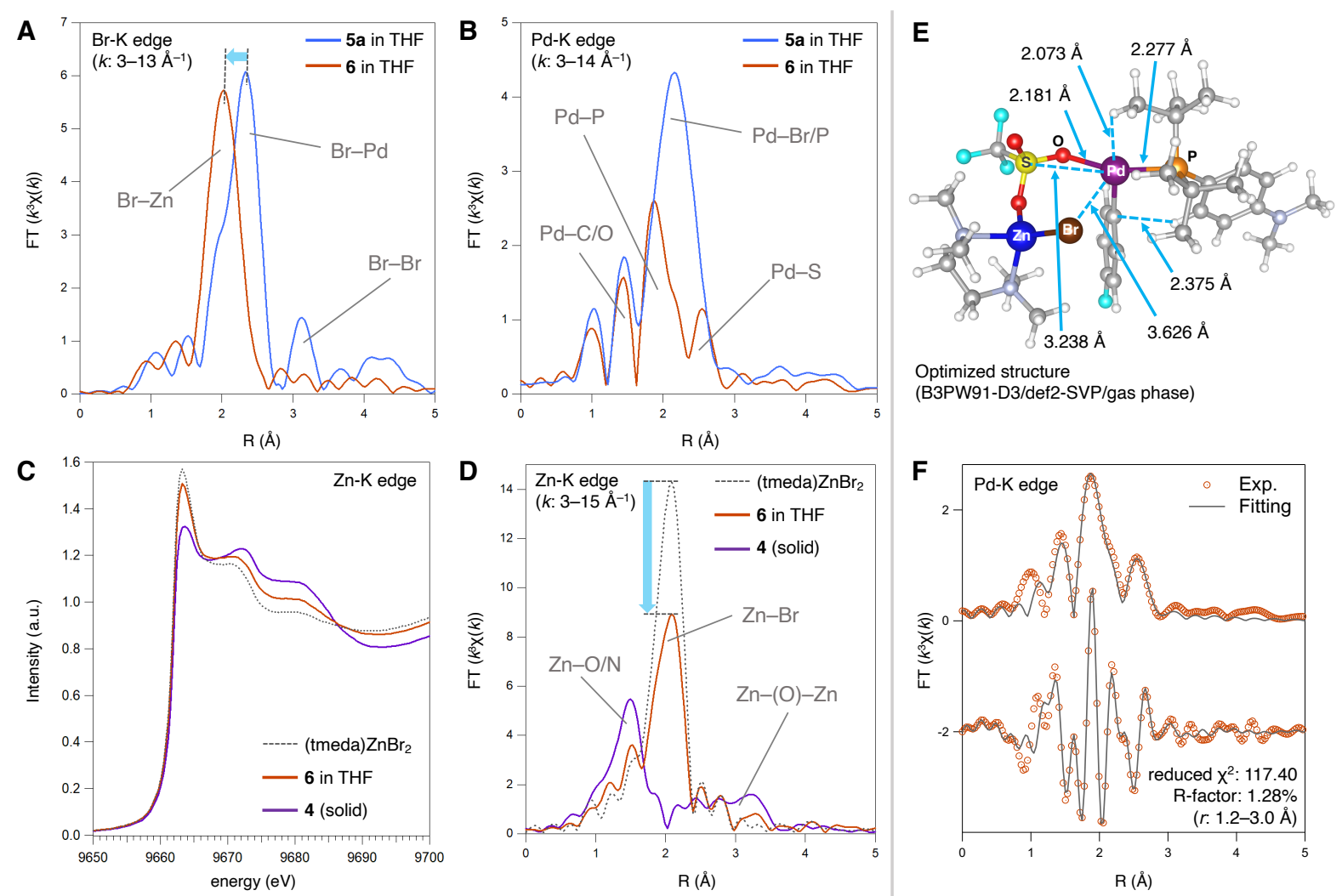

Optimized structure
(B3PW91-D3/def2-SVP/gas phase)
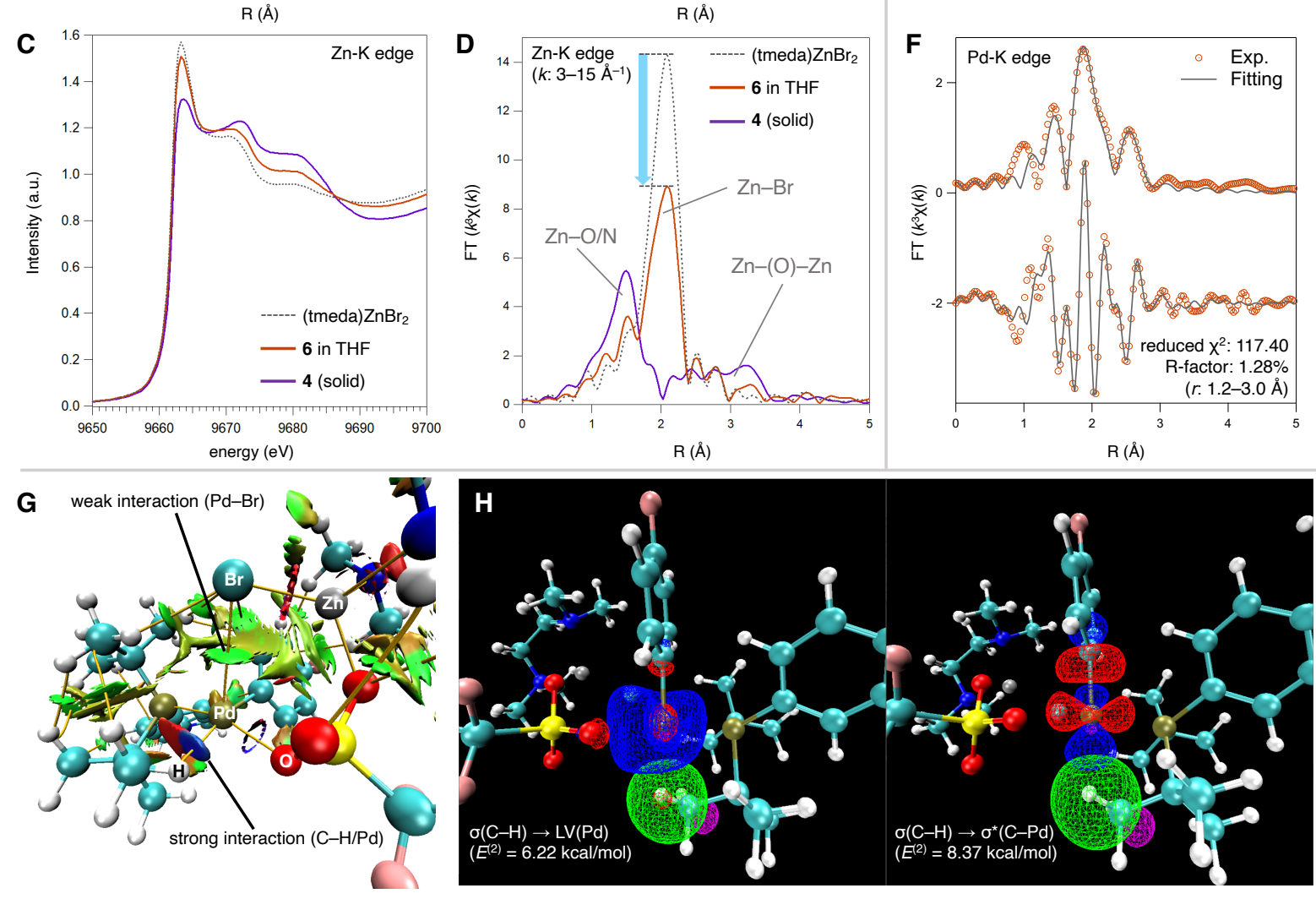

Fig. 4. XAS and electron density analyses of intermediate 6. A, Br-K edge extended X-ray absorption fine structure (EXAFS). B, Pd-K edge EXAFS. C, Zn-K edge X-ray absorption near edge structure (XANES). D, Zn-K edge EXAFS. E, Reconstructed structure of $\mathbf{6}$ according to density functional theory (DFT) calculations. F, Plots of the fitted curve for the Pd-K edge EXAFS in $r$-space: magnitude and its imaginary part. G, Isosurface of noncovalent interactions (NCIs) and bond paths obtained from quantum theory of atoms-in-molecules (QTAIM) analysis. $\mathbf{H}$, Reference orbitals in natural bond orbital (NBO) basis; $[\sigma(\mathrm{C}-\mathrm{H}) \rightarrow \mathrm{LV}(\mathrm{Pd})]$ and $[\sigma(\mathrm{C}-$ $\left.\mathrm{H}) \rightarrow \sigma^{*}(\mathrm{C}-\mathrm{Pd})\right]$.

Based on the estimated structure of $\mathbf{6}$, theoretical surveys were conducted to reveal the origin of the thermostability. The hydrogen atom of the tert-butyl group in the Amphos ligand is located near the vacant coordination site of the palladium centre at the distance of $2.073 \AA$ (Fig. $4 \mathrm{E}$ ), which implies an attractive interaction. To gain information about electrostatic interactions, we analyzed the noncovalent interactions $(\mathrm{NCIs})^{20}$ and identified a strong interaction between the palladium centre and the hydrogen atom of Amphos (Fig. 4G, blue isosurface). The quantum 
theory of atoms-in-molecules (QTAIM) ${ }^{21}$ analysis also revealed the presence of bond critical point (BCP) between the palladium and hydrogen atoms with a relatively high electron density $\left(\rho_{\text {bcp }}(r)=0.250 \mathrm{e}^{-3}\right)$ and Wiberg bond index $(\mathrm{WBI})$ of 0.167 , which indicates significant interaction (Table $\mathrm{S} 15)$. The natural bond orbital (NBO) analysis showed electron donations from the $\sigma(\mathrm{C}-\mathrm{H})$ orbital to the vacant Pd orbital $\left(E^{(2)}=6.22 \mathrm{kcal} / \mathrm{mol}\right)$ and $\sigma^{*}(\mathrm{C}-\mathrm{Pd})$ orbital $\left(E^{(2)}=8.37 \mathrm{kcal} / \mathrm{mol}\right)$ (Fig. $\left.4 \mathrm{H}\right)$. The NBO analysis indicated moderate electron donation (Net $\left.E^{(2)}=14.59 \mathrm{kcal} / \mathrm{mol}\right)$ from the $\sigma(\mathrm{C}-\mathrm{H})$ orbital of the proximal tert-butyl groups to the cationic palladium centre, which contributed to the high stability of intermediate $\mathbf{6}$. We also identified a weak NCI between the palladium centre and the eliminated bromine atom (Fig. 4G, green isosurface), which was supported by the low electron density value $\left(\rho_{\mathrm{bcp}}(r)=0.060 \mathrm{e}^{-3}\right)$ and WBI (0.091) at the BCP in QTAIM analysis. This result suggests that the sterically hindered bromine atom at the remote apical position of palladium $(\mathrm{Pd}-\mathrm{Br}$ : $3.626 \AA)$ is loosely coordinated and enhances not only the kinetic but also thermodynamic stability of 6 .

We proposed a mechanism for the base-free SMC reaction (Fig. 5). The reaction commences with the reduction of the palladium(II) precursor with potassium phenyl(trifluoro)borate (2a) to afford coordinately unsaturated mono(amphos)palladium( $(0)$ A. The oxidative addition of $\mathbf{1}$ provides arylpalladium(II) bromide $\mathbf{B}$, which exists mainly as dimer 5a. Then, the debromination by the zinc monomer $(\mathbf{C})$ generated from $\mathbf{4}$ affords the bimetallic intermediate (6), in which boron trifluoride, formed in the transmetalation, is assumed to capture the hydroxy group of $\mathbf{C}$. We estimate that $\mathbf{6}$ is coordinately saturated with a square planar structure and is therefore inactive for direct transmetalation. The removal of the zinc moiety provides coordinately unsaturated cationic complex $\mathbf{D}$, which reacts with $\mathbf{2 a}$ to give diarylpalladium(II) G. Finally, the reductive elimination of biaryl $\mathbf{3}$ regenerates $\mathbf{A}$ to complete the catalytic cycle. The liberated zinc species $\mathbf{E}$ serves as a Lewis acid again to be deactivated as zinc dibromide complex F, which was characterised by XAS measurements (Figs. S16 and S17). The DFT calculations (Figs. S19-S22) indicate that the dissociation of the bromide $(\mathbf{B}+\mathbf{C}$ to $\mathbf{6})$ is favourable $(\Delta G=-13.7 \mathrm{kcal} / \mathrm{mol})$. The following zinc removal process $(\mathbf{6}$ to $\mathbf{D}+\mathbf{E})$ was slightly endergonic $(+5.7 \mathrm{kcal} / \mathrm{mol})$, supporting our hypothesis that transmetalation-active species $\mathbf{D}$ forms in equilibrium and predominantly exists as a relatively stable masked intermediate (6). The energy barrier for the base-free transmetalation $(\mathbf{D}+\mathbf{2 a}$ to $\mathbf{G})$ was estimated to be +20.7 $\mathrm{kcal} / \mathrm{mol}$, consistent with the experimental result that the stoichiometric transmetalation occurred without heating. 


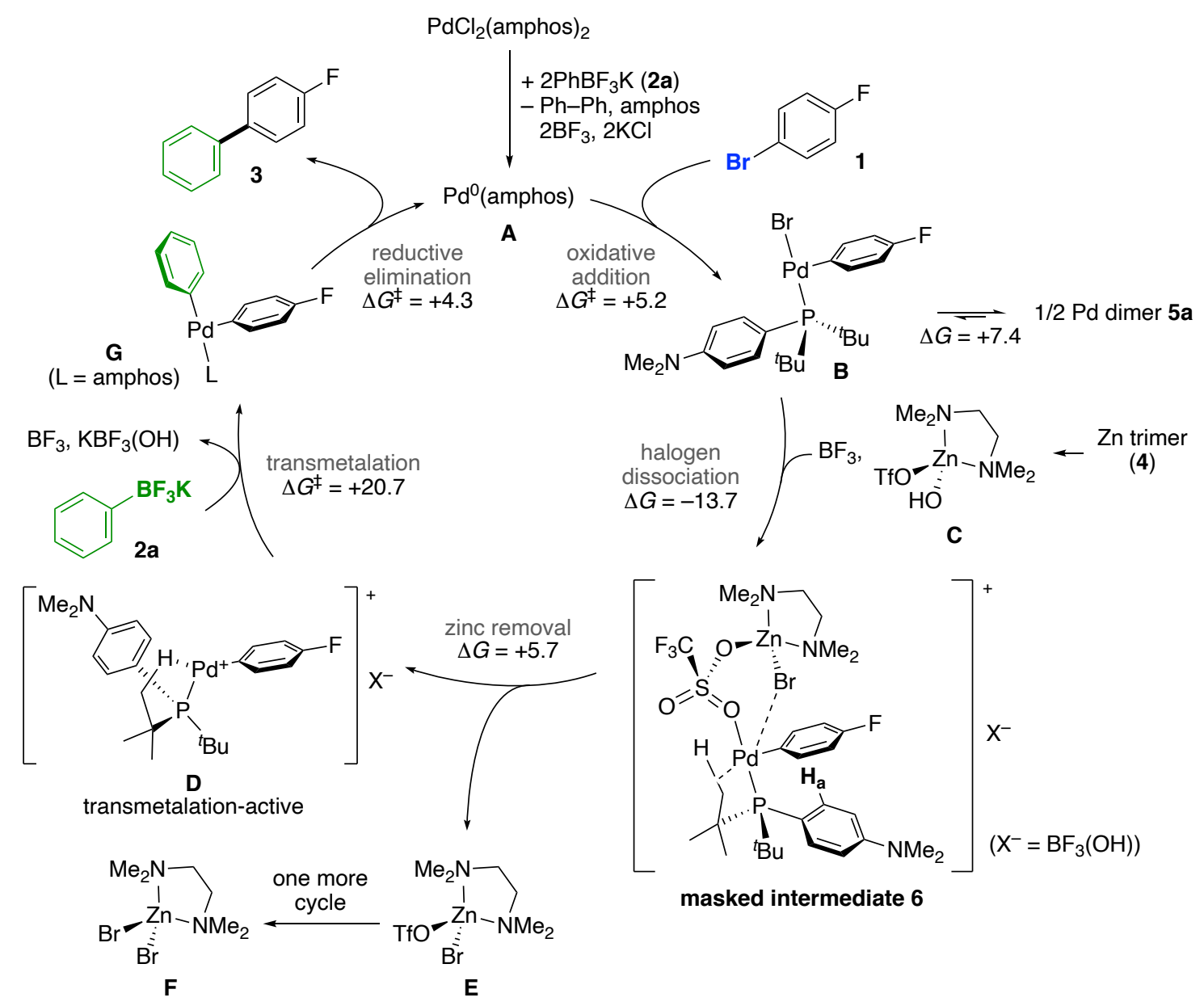

Fig. 5. Plausible mechanism. Gibbs free energies $\left(\Delta G\right.$ and $\left.\Delta G^{\ddagger}, 298.15 \mathrm{~K}, 1 \mathrm{~atm}\right)$ are shown in $\mathrm{kcal} / \mathrm{mol} . \mathbf{H}_{\mathbf{a}}$ in intermediate $\mathbf{6}$ indicates the proton that showed the exceptionally high magnetic field shift of the peak observed in ${ }^{1} \mathrm{H}$ NMR analysis (Fig. 3C).

The substrate scope of the base-free SMC reaction was explored mainly using aryl bromides and potassium aryl(trifluoro)borates. A broad range of aryl(trifluoro)borates with various substituents participated in the reaction to provide biaryls in high yields (Fig. 6A). The nonbasic conditions allowed the use of substrates with base-sensitive groups, including acidic functionals such as phenol $(\mathbf{1 2}, \mathbf{3 8})$ and carboxy (14) moieties. Perfluorophenyl (16-18) and heteroaryl (19-24) substrates were found compatible for giving desired biaryls as well. Alkenyl- and alkynylborates, including a boryl(fluoro)alkene unit, ${ }^{22}$ participated in the reaction smoothly to afford 25-27 (Fig. 6B). Our approach often showed a considerable efficiency compared to those of previously established methods, as the reactions with selected substrates under general conditions using potassium organo(trifluoro)borates ${ }^{23}$ scarcely yielded products 14, 16, and 26. When aryl chlorides were used as electrophiles, the desired products were not obtained under the standard conditions, despite the fact that the palladium catalysis with an Amphos ligand is generally utilised for the SMC reaction with aryl chlorides. ${ }^{24} \mathrm{We}$ reoptimized the palladium catalyst and found that the use of a biaryl(dialkyl)phosphines was effective for the coupling reaction in the case of aryl chlorides (Fig. 6C and Table S5). The robustness of the reaction to various functional groups prompted us to apply this method to the late-stage functionalization of bioactive compounds. The SMC reaction of indomethacin methyl ester 
with aryl bromides having various functional groups, such as diformyl, unprotected amino, and coumarin moieties, proceeded uneventfully to provide the arylated products (30-39, Fig. 6D). Notably, we found that the (pinacolato)boryl group remained intact under our conditions, which indicated the potential application of this method for sequential coupling reactions. ${ }^{25}$ The optimized conditions were also applicable to the synthesis or modification of bioactive compounds, such as TMD-512 (40), ${ }^{26}$ and the arylation of commercial medicines (41-44) bearing various functional groups, demonstrating the broad substrate scope of this method (Fig. $6 \mathrm{E})$. 


\section{$A r^{2}-\mathbf{X}+\mathrm{B}-A r^{2} \longrightarrow A r^{2}-A r^{2}$ \\ ( $\mathrm{X}=\mathrm{Br}$ or $\mathrm{Cl}, 1$ equiv) $\quad$ (1.1 equiv)}

A. Aryl(trifluoro)borates with $\mathrm{Ar}^{1} \mathrm{Br}$

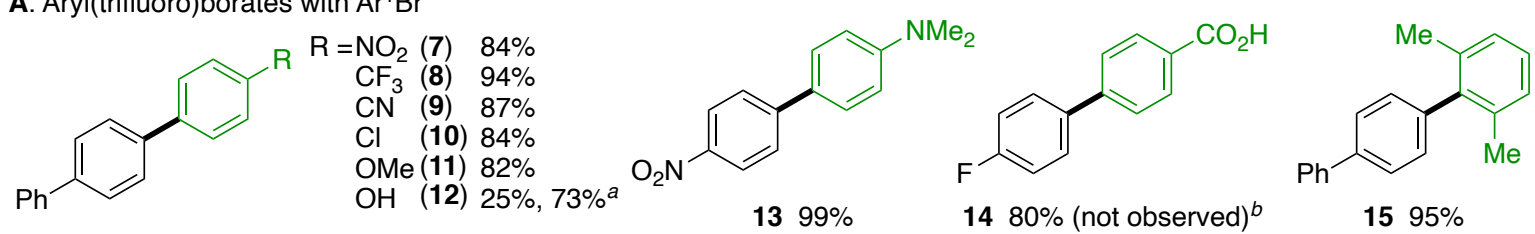<smiles>Fc1cccc(F)c1-c1ccc(-c2ccccc2)cc1</smiles>

$1693 \%(8 \%)^{b}$<smiles>Fc1cc(F)c(F)c(-c2ccc(-c3ccccc3)cc2)c1F</smiles>

$1779 \%$<smiles>Fc1c(F)c(F)c(-c2ccc(-c3ccccc3)cc2)c(F)c1F</smiles>

$1879 \%$<smiles></smiles>

$1960 \%$<smiles>c1ccc(-c2ccc(-c3ccoc3)cc2)cc1</smiles>

$2075 \%$<smiles>Clc1ncccc1-c1ccc(-c2ccccc2)cc1</smiles>

$2146 \%, 79 \%^{\circ}$

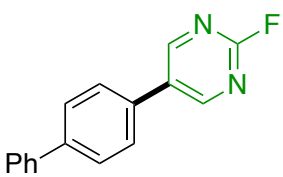

$2297 \%$<smiles>c1ccc(-c2ccc(-c3cccs3)cc2)cc1</smiles>

$2396 \%$

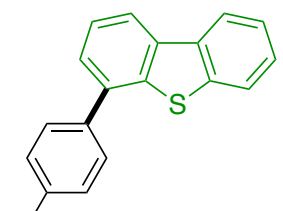

$2498 \%$
B. Alkenyl- and alkynyl(trifluoro)borates (from $\mathrm{Ar}^{-1} \mathrm{Br}$ and $\mathrm{RBF}_{3} \mathrm{~K}$ )<smiles>C=C(C)c1ccc(-c2ccc(-c3ccccc3)cc2)cc1</smiles>

$2597 \%$<smiles>Fc1ccc(C#Cc2ccccc2)cc1</smiles>

$2767 \%$

C. Aryl chlorides (from $\mathrm{Ar}^{1} \mathrm{Cl}$ and $4-\mathrm{FC}_{6} \mathrm{H}_{4} \mathrm{BF}{ }_{3} \mathrm{~K}$ )<smiles>Fc1ccc(-c2ccccc2)cc1</smiles>
$\mathrm{OHC}$<smiles>COc1ccc(-c2ccc(F)cc2)cc1</smiles>

$2886 \%$

$2965 \%$

D. Aryl bromides with indomethacin derivative (from $\mathrm{Ar}^{1} \mathrm{Br}$ and indomethacin- $\mathrm{BF}_{3} \mathrm{~K}$ )<smiles>COc1ccc2c(c1)c(CC(C)=O)c(C)n2C(=O)c1ccc(I)cc1</smiles><smiles>CN(C)c1ccc(N([O])c2ccc([N+](=O)[O-])cc2C=O)cc1C=O</smiles>

$3193 \%$ 32 99\%<smiles>Nc1ccccc1C(=O)c1ccc([N+](=O)[O-])cc1</smiles>

$3481 \%$

$3566 \%$<smiles></smiles>

$3791 \%$<smiles>O=c1cc(O)c2ccc([N+](=O)[O-])cc2o1</smiles>

$3895 \%$<smiles></smiles>

$3093 \%$<smiles>Cc1cc(C)c([N+](=O)[O-])c(C)c1</smiles>

33 93\%<smiles>[Nb]c1ccccn1</smiles>

$3687 \%$<smiles>[N+]=[N+]c1cncc2ccccc12</smiles>

$3974 \%$

E. Late-stage modification (from $\mathrm{Ar}^{1} \mathrm{X}$ and $\mathrm{ArBF}_{3} \mathrm{~K}$ )<smiles>CCNc1sc2c(OCCN(CC)CC)c(-c3ccc(O)cc3)ccc2c1C(=O)OCC</smiles>

$4056 \%$ TMD-512 (Ar $\left.{ }^{1} \mathrm{Br}\right)$<smiles>OC1(c2ccc(C(F)(F)F)c(-c3ccccc3)c2)CCN(CCCC(c2ccc(F)cc2)c2ccc(F)cc2)CC1</smiles><smiles>COc1ccc2c(c1)c(CC(=O)O)c(C)n2C(=O)c1ccc(-c2ccc(F)cc2)cc1</smiles>

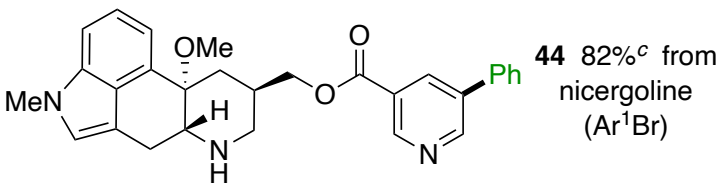


Fig. 6. Substrate scope. Reaction conditions for $\mathrm{ArBr}(0.200 \mathrm{mmol}, 1$ equiv): potassium organo(trifluoro)borate (1.1 equiv), $\mathrm{PdCl}_{2}$ (amphos) 2 ( $\left.2 \mathrm{~mol} \%\right), 4$ ( 0.72 equiv/ $\left.\mathrm{Zn}\right), \mathrm{THF}(1 \mathrm{~mL})$, $80{ }^{\circ} \mathrm{C}, 3-24 \mathrm{~h}$. Reaction conditions for $\mathrm{ArCl}$ ( $0.200 \mathrm{mmol}, 1$ equiv): organoboron (1.1 equiv), (cod)Pd( $\left.\mathrm{CH}_{2} \mathrm{TMS}\right)_{2}(4 \mathrm{~mol} \%)$, XPhos (10 mol\%), 4 (0.72 equiv/Zn), CPME $(1 \mathrm{~mL}), 120{ }^{\circ} \mathrm{C}$, 3-6 h. Isolated yields are shown. Moieties drawn with black or green are derived from organohalides or organoborons, respectively. A, Scope of potassium aryl(trifluoro)borates. B, Reaction with potassium alkenyl- and alkynyl(trifluoro)borates. C, Reactions with aryl chlorides. D, Synthesis of indomethacin methyl ester derivatives with various aryl bromides. E, Late-stage modification of bioactive compounds. ${ }^{a}$ An arylboronic acid (1.5 equiv) was used instead of a potassium aryl(trifluoro)borate. ${ }^{b 19} \mathrm{~F}$ NMR yields, given in the parentheses, were obtained under the following conditions: $\mathrm{ArBr}(0.200 \mathrm{mmol}, 1$ equiv), potassium organo(trifluoro)borate (1.1 equiv), $\mathrm{Pd}(\mathrm{OAc})_{2}$ ( $4 \mathrm{~mol} \%$ ), RuPhos (4 mol\%), $\mathrm{Na}_{2} \mathrm{CO}_{3}$ (2 equiv), $\mathrm{EtOH}(1 \mathrm{~mL}), 85^{\circ} \mathrm{C}, 3 \mathrm{~h} .{ }^{c} 5 \mathrm{~mol} \%$ of $\mathrm{PdCl}_{2}$ (amphos) $)_{2}$ was used. ${ }^{d} 1 \mathrm{mmol}$ scale.

In summary, we have established a base-free condition for the SMC reaction of general organohalides with organoborons by using a zinc complex. The present method, involving the controlled release of a transmetalation-active organopalladium(II) species, allows the performing of the SMC reactions in non-basic media and renders substrates with base-sensitive moieties available, improving the synthetic utility. This approach, which controls the release of active species mediated by a Lewis acid, can innovate cross-coupling chemistry because transmetalation is a fundamental step in transition-metal-catalysed reactions. Furthermore, this concept has the potential to enhance the utility of chemical processes involving the generation of cationic organometallic intermediates, such as electrophilic functionalisation of carbonhydrogen bonds ${ }^{27}$ and polyolefin synthesis, ${ }^{28}$ thus improving the efficiency of chemical production and lowering the environmental burden. Further investigations to explore Lewis acid catalysts for the base-free SMC reaction and discover the scope of the controlled-release concept are currently underway.

\section{References and Notes}

1. Miyaura, N. \& Suzuki, A. Palladium-Catalyzed Cross-Coupling Reactions of Organoboron Compounds. Chem. Rev. 95, 2457-2483 (1995).

2. Schneider, N., Lowe, D. M., Sayle, R. A., Tarselli, M. A. \& Landrum, G. A. Big Data from Pharmaceutical Patents: A Computational Analysis of Medicinal Chemists' Bread and Butter. J. Med. Chem. 59, 4385-4402 (2016).

3. Lennox, A. J. J. \& Lloyd-Jones, G. C. Transmetalation in the Suzuki-Miyaura Coupling: The Fork in the Trail. Angew. Chem. Int. Ed. 52, 7362-7370 (2013).

4. Cox, P. A., Reid, M., Leach, A. G., Campbell, A. D., King, E. J. \& Lloyd-Jones, G. C. Base-Catalyzed Aryl-B $(\mathrm{OH})_{2}$ Protodeboronation Revisited: From Concerted Proton Transfer to Liberation of a Transient Aryl Anion. J. Am. Chem. Soc. 139, 13156-13165 (2017).

5. Cox, P. A., Leach, A. G., Campbell, A. D. \& Lloyd-Jones, G. C. Protodeboronation of Heteroaromatic, Vinyl, and Cyclopropyl Boronic Acids: pH-Rate Profiles, Autocatalysis, and Disproportionation. J. Am. Chem. Soc. 138, 9145-9157 (2016). 
6. Suzuki, A. Cross-Coupling Reactions Of Organoboranes: An Easy Way To Construct CC Bonds (Nobel Lecture). Angew. Chem. Int. Ed. 50, 6722-6737 (2011).

7. Lennox, A. J. J. \& G. C. Lloyd-Jones, Selection of boron reagents for Suzuki-Miyaura coupling. Chem. Soc. Rev. 43, 412-443 (2014).

8. Valente, C. \& Organ, M. G. "Contemporary Suzuki-Miyaura Reactions" in Boronic Acids, D. G. Hall, Ed. (Wiley, 2011), vol. 2, chap. 4.

9. Cammidge, A. N., Goddard, V. H. M., Gopee, H., Harrison, N. L., Hughes, D. L., Schubert, C. J., Sutton B. M., Watts, G. L. \& Whitehead, A. J. Org. Lett. 8, 4071-4047 (2006).

10. Yamamoto, Y., Takizawa, M., Yu, X.-Q. \& Miyaura, N. Angew. Chem. Int. Ed. 47, 928931 (2008).

11. Malapit, C. A., Bour, J. R., Brigham, C. E. \& Sanford, M. S. Base-free nickel-catalyzed decarbonylative Suzuki-Miyaura coupling of acid fluorides. Nature 563, 100-104 (2018).

12. Darses, S., Jeffery, T., Genet, J.-P., Brayer, J.-L.\& Demoute, J.-P. Cross-coupling of arenediazonium tetrafluoroborates with arylboronic acids catalyzed by palladium. Tetrahedron Lett. 37, 3857-3860 (1996).

13. Chen, L., Sanchez, D. R., Zhang, B. \& Carrow, B. P. "Cationic" Suzuki-Miyaura Coupling with Acutely Base-Sensitive Boronic Acids. J. Am. Chem. Soc. 139, 1241812421 (2017).

14. Chen, L., Francis, H. \& Carrow, B. P. An “On-Cycle” Precatalyst Enables RoomTemperature Polyfluoroarylation Using Sensitive Boronic Acids. ACS Catal. 8, 29892994 (2018).

15. Sanhueza, I. A., Klauck, F. J. R., Senol, E., Keaveney, S. T., Sperger, T. \& Schoenebeck, F. Base-Free Cross-Coupling of Aryl Diazonium Salts in Methanol: Pd ${ }^{\mathrm{II}}$-Alkoxy as Reactivity-Controlling Intermediate. Angew. Chem. Int. Ed. 60, 7007-7012 (2021).

16. Molander, G. A. \& Jean-Gérard, L. "Organotrifluoroborates: Organoboron Reagents for the Twenty-First Century" in Boronic Acids, D. G. Hall, Ed. (Wiley, 2011), vol. 2, chap. 11.

17. Gillis, E. P. \& Burke, M. D. A Simple and Modular Strategy for Small Molecule Synthesis: Iterative Suzuki-Miyaura Coupling of B-Protected Haloboronic Acid Building Blocks. J. Am. Chem. Soc. 129, 6716-6717 (2007).

18. Noguchi, H., Hojo, K. \& M. Suginome, Boron-Masking Strategy for the Selective Synthesis of Oligoarenes via Iterative Suzuki-Miyaura Coupling. J. Am. Chem. Soc. 129, 758-759 (2007).

19. Zabinsky, S. I., Rehr, J. J., Ankudinov, A., Albers, R. C. \& Eller, M. J. Multiple-scattering calculations of x-ray-absorption spectra. Phys. Rev. B, 52, 2995-3009 (1995).

20. Johnson, E. R., Keinan, S., Mori-Sánchez, P., Contreras-García, J., Cohen, A. J. \& Yang, W. Revealing Noncovalent Interactions. J. Am. Chem. Soc. 132, 6498-6506 (2010).

21. Bader, R. F. W. Atoms in Molecules. Acc. Chem. Res. 18, 9-15 (1985). 
22. Isoda, M., Uetake, Y., Takimoto, T., Tsuda, J., Hosoya, T. \& Niwa, T. Convergent Synthesis of Fluoroalkenes Using a Dual-Reactive Unit. J. Org. Chem. 86, 1622-1632 (2021).

23. Molander, G. A., Canturk, B. \& Kennedy, L. E. Scope of the Suzuki-Miyaura CrossCoupling Reactions of Potassium Heteroaryltrifluoroborates. J. Org. Chem. 74, 973-980 (2009).

24. Guram, A. S., Wang, X., Bunel, E. E., Faul, M. M., Larsen, R. D. \& Martinelli, M. J. New Catalysts for Suzuki-Miyaura Coupling Reactions of Heteroatom-Substituted Heteroaryl Chlorides. J. Org. Chem. 72, 5104-5112 (2007).

25. Lehmann, J. W., Blair, D. J. \& Burke, M. D. Towards the generalized iterative synthesis of small molecules. Nat. Rev. Chem. 2, 0115 (2018).

26. Shimizu, S., Hosoya, T., Murohashi, M. \& Yoshida, S. Benzothiophene compound, alternative autophagy-inducing agent and anticancer drug including benzothiophene compound as active ingredient, and method for screening for compounds having anticancer activity. WO 2013118842.

27. Gensch, T., Hopkinson, M. N., Glorius, F. \& Wencel-Delord, J. Mild metal-catalyzed CH activation: examples and concepts. Chem. Soc. Rev. 45, 2900-2936 (2016).

28. Chen, C. Designing catalysts for olefin polymerization and copolymerization: beyond electronic and steric tuning. Nat. Rev. Chem. 2, 6-14 (2018).

\section{Acknowledgements:}

We thank Prof. Dr. T. Ritter (Max-Planck-Institut für Kohlenforschung, Deutschland) for valuable comments on a draft of the manuscript. XAS measurements were performed at the BL14B2 of SPring-8 with the approval of the Japan Synchrotron Radiation Research Institute (JASRI) (Proposal Nos. 2020A1732 and 2020A1871), and at the BL-12C of KEK under the approval of the Photon Factory Program Advisory Committee (Proposal No. 2020G006). Theoretical studies were performed at RIKEN on Hokusai Big Waterfall (BW) (Proposal No. Q20509) and Research Center for Computational Science, Okazaki, Japan.

\section{Funding:}

Japan Society for the Promotion of Science (JSPS) KAKENHI Grant-in-Aid for Scientific Research(C) 20K05521 (TN)

Japan Society for the Promotion of Science (JSPS) KAKENHI Grant-in-Aid for EarlyCareer Scientists 20K15279 (YU)

Japan Society for the Promotion of Science (JSPS) KAKENHI Grant-in-Aid for EarlyCareer Scientists 19K16332 (MI)

The Japan Agency for Medical Research and Development (AMED) under grant no. 20am0101098j0005 (Platform Project for Supporting Drug Discovery and Life Science Research, BINDS) (TN, TH)

Research Grant from Hyogo Science and Technology Association (FY2021) (TN)

Mitsubishi Gas Chemical Award in Synthetic Organic Chemistry, Japan (YU) 
The Pioneering Project "Chemical Probe" from RIKEN (TH)

RIKEN-Osaka University Science and Technology Hub Collaborative Research Program from RIKEN and Osaka University (TN, YU)

\section{Author contributions:}

Conceptualization: TN, MI, TH

Formal analysis: TN, YU

Methodology: TN, YU, MI, DH

Investigation: TN, YU, MI, TT, MN, DH

Supervision: TN, HS, TH

Writing - original draft: TN, YU

Writing - review \& editing: TN, YU, HS, TH

Competing interests: Authors declare that they have no competing interests.

Data and materials availability: "The main data are available in the main text or the supplementary materials. Data for X-ray crystal structures of $\mathbf{4}$ and $\mathbf{5 a}$ are available free of charge from the Cambridge Crystallographic Data Center under reference numbers CCDC 2073815 and CCDC 2073816, respectively.

\section{Supplementary Information}

Materials and Methods

Supplementary Text

Figs. S1 to S22

Tables S1 to S16

References (1-71)

Cartesian coordinates of optimized structures

NMR Spectra 